\title{
IgM rheumatoid factor (RF), IgA RF, IgE RF, and IgG RF detected by ELISA in rheumatoid arthritis
}

\author{
M GIOUD-PAQUET, ${ }^{1}$ M AUVINET, ${ }^{2}$ T RAFFIN, ${ }^{3}$ P GIRARD, \\ M BOUVIER, ${ }^{1}$ E LEJEUNE, ${ }^{1}$ AND J C MONIER
}

From the ${ }^{1}$ Service de Rhumatologie, Hopital des Charpennes, 69100 Villeurbanne; the 'Laboratoire d'Immunologie, Faculté A-Carrel, 69008 Lyon; and the ${ }^{3}$ Laboratoire de Recherche API, La Balme Les Grottes, 38390 Montalieu-Vercieu, France

SUMMARY One hundred patients with rheumatoid arthritis (RA), of whom 73 were seropositive by latex or Waaler-Rose (WR) assays, or both, 100 healthy subjects, and 102 diseased controls (22 patients with systemic lupus erythematosus (SLE) and 80 with bronchial asthma) were evaluated for the presence of IgM rheumatoid factor (RF), IgA RF, IgE RF, and IgG RF by an enzyme linked immunosorbent assay (ELISA). Ninety two per cent, $65 \%, 68 \%$, and $66 \%$ of the patients with RA were found to be positive for $\operatorname{IgM}, \operatorname{IgA}, \operatorname{IgE}$, and $\operatorname{IgG}$ respectively. A positive correlation existed between the levels of IgM RF and IgA RF on the one hand and disease activity on the other, and the levels of IgM RF and IgA RF correlated with the levels of circulating immune complexes as measured by a $\mathrm{C} 1 \mathrm{q}$ binding assay. The presence of extraarticular features also correlated positively with the levels of IgA RF and IgE RF. Five out of six patients with Sjögren's syndrome had very high levels of IgA RF. Of 47 patients typed for HLADR, DR1 and DR2 were significantly more frequent in those with the highest levels of IgM RF. Conversely, DR3 was associated with low levels or absence of IgA RF and IgE RF. These results suggest that immune response genes may regulate the level of different RF isotypes. The frequencies of $\operatorname{IgM}, \operatorname{IgA}$, IgE, and $\operatorname{IgG} \mathrm{RF}$ were $59 \%, 36 \%, 9 \%$, and $27 \%$ respectively in SLE and $25 \%, 2.5 \%, 70 \%$, and $59 \%$ in bronchial asthma.

Key words: systemic lupus erythematosus (SLE).

Standard assays for rheumatoid factor (RF), such as the latex or Waaler-Rose (WR) tests, favour the detection of the IgM RF, which is found in only $60-70 \%$ of RA sera. ${ }^{2}$ Immunofluorescent techniques, radioimmunoassay, and enzyme immunoassay enable measurement of the isotype specific IgM, $\operatorname{IgA}$, IgG, and IgE RF. ${ }^{3-6}$ It is necessary to re-evaluate the notion of seronegative RA determined by these agglutination reactions in the context of the greater sensitivity of more recent techniques.

The aim of this study was the detection (using ELISA) of IgM, IgG, IgA, and IgE RF in 100 patients with RA, 22 with SLE, and 80 with bronchial asthma, to compare the results with the

Accepted for publication 26 June 1986.

Correspondence to Dr J C Monier, Faculté de Médecine Alexis Carrel, Ruc Guillaume Paradin, 69372 - Lyon Cedex 02, France. latex and WR tests, and to consider the relation between RF isotypes and clinical findings such as disease activity, systemic manifestations, and HLADR antigens.

\section{Patients and methods}

\section{PATIENTS}

One hundred patients with RA were studied: 86 women and 14 men with ages ranging from 19 to 86 years. They fulfilled the American Rheumatism Association (ARA) criteria. ${ }^{7}$ Clinical evaluation of disease activity was performed on the basis of the duration of morning stiffness, the number of diseased joints, and erythrocyte sedimentation rate. The disease was thus graded as very (IV), moderately (III), slightly active (II), or inactive (I). ${ }^{89}$ Radiographic staging of RA was carried out according to the technique described by Stein- 
brocker et al. ${ }^{10}$ Blood was drawn for estimation of erythrocyte sedimentation rate, isotype specific ELISA, latex and WR tests, circulating immune complexes by the $\mathrm{C} 1 \mathrm{q}$ binding test, ${ }^{11}$ antinuclear antibodies (indirect immunofluorescent techniques on blood smears), and anti-double stranded deoxyribonucleic acid antibodies (Farr assay). HLA-A, B, $C$, and DR typing was performed in 47 patients.

We also studied the sera of 22 patients with SLE ( 21 women and one man) with ages ranging from 18 to 80 years. They were diagnosed on the basis of the presence of at least four of the ARA revised criteria. $^{12}$ Eighty sera from young patients with bronchial asthma were also studied. Serum samples from 100 healthy subjects were used to determine the upper limit of normal activity for the different $\mathrm{RF}$ isotypes (mean (2 SD)).
DETERMINATION OF RF Latex fixation tests were performed by the Singer and Plotz technique, ${ }^{13}$ a titre of $>1 / 80$ being? considered positive. WR tests were determined byc the technique proposed by Eyquem et l $^{14}$ and $a$ titre of $>1 / 32$ was considered positive.

ENZYME LINKED IMMUNOSORBENT ASSAY ڤै (E L IS A )

Flat well microplates (Nunc) were coated with $100 \mu \mathrm{l}^{\circ}$ of aggregated human IgG $(25 \mu \mathrm{g} / \mathrm{ml})$. Phosphate $\vec{\omega}$ buffered saline $(100 \mu \mathrm{l})$ containing $5 \%$ bovine serum albumin were used to coat the control without antigen. The plates were then incubated with test: serum samples diluted in phosphate buffered saline $/=$ Tween-20 containing $5 \%$ bovine serum albumin inos triplicate. Serum sample dilutions used were $1 / 40$ for

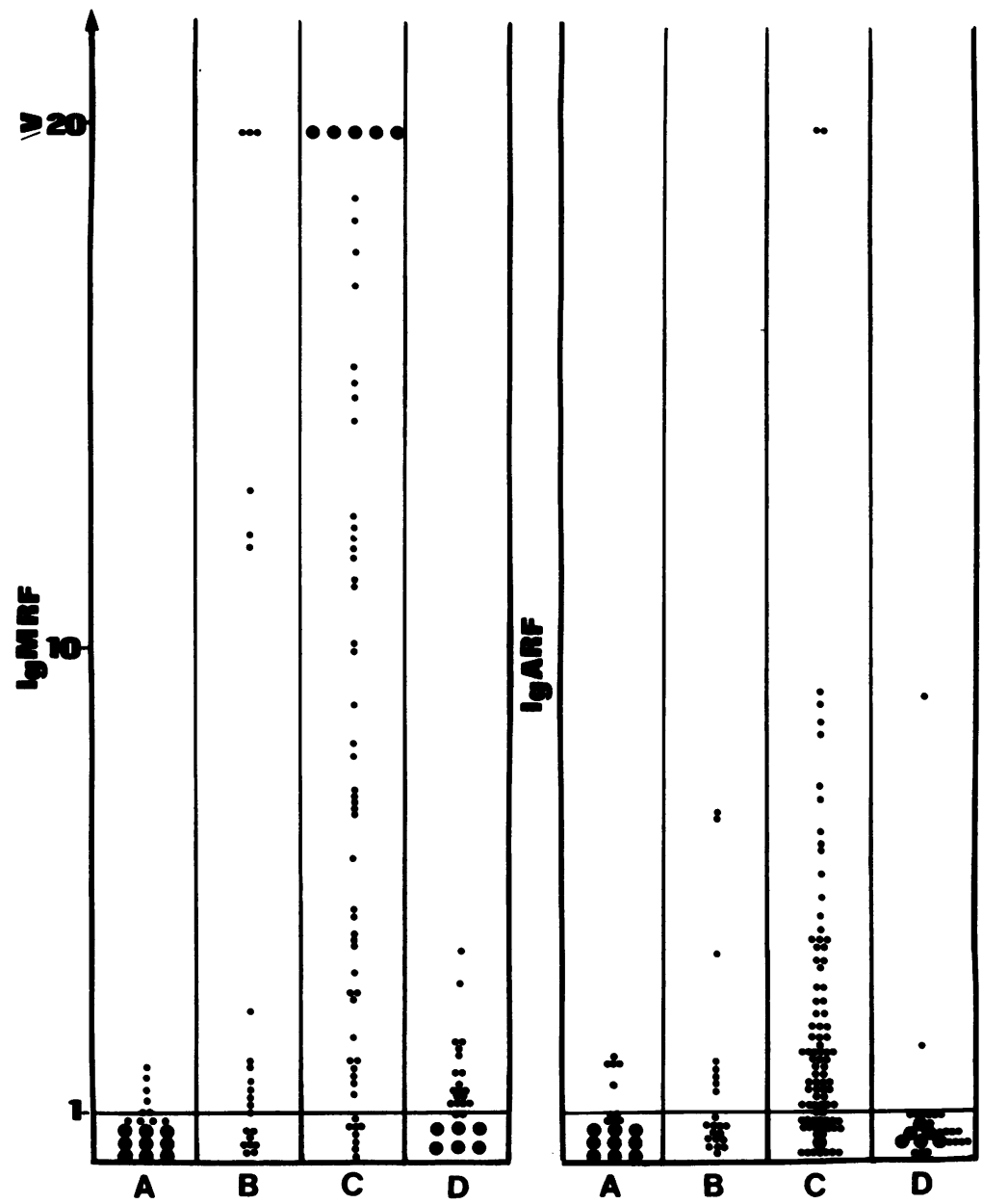

Fig. 1 IgM RF and IgA $R F$ distribution in $(A) 100$ control sera, (B) 22 SLE sera, (C) $100 R \dot{8}$ sera, and $(D) 80$ bronchial asthmw sera by ELISA (OD patient sera/OD upper limit control sera)울 $\bullet=$ one serum; $=10$ sera. 
Table 1 Occurrence of IgM, IgG, and IgE RF in 100 patients with $R A$ determined by an ELISA

\begin{tabular}{|c|c|c|c|c|}
\hline \multirow[t]{2}{*}{$E L I S A$} & & \multicolumn{2}{|c|}{ Latex/WR test } & \multirow[t]{2}{*}{$\%$} \\
\hline & & $\begin{array}{l}\text { Seropositive } \\
(n=73)\end{array}$ & $\begin{array}{l}\text { Seronegative } \\
(n=27)\end{array}$ & \\
\hline IgM RF & $\begin{array}{l}+ \\
-\end{array}$ & $\begin{array}{r}73 \\
0\end{array}$ & $\begin{array}{r}19 \\
8\end{array}$ & 92 \\
\hline IgA RF & $\begin{array}{l}+ \\
-\end{array}$ & $\begin{array}{l}62 \\
11\end{array}$ & $\begin{array}{r}3 \\
24\end{array}$ & 65 \\
\hline IgG RF & $\begin{array}{l}+ \\
-\end{array}$ & $\begin{array}{l}50 \\
23\end{array}$ & $\begin{array}{l}16 \\
11\end{array}$ & 66 \\
\hline IgE RF & $\begin{array}{l}+ \\
-\end{array}$ & $\begin{array}{l}59 \\
14\end{array}$ & $\begin{array}{r}9 \\
18\end{array}$ & 68 \\
\hline
\end{tabular}

IgM RF and $\operatorname{IgA} R F, 1 / 6$ for IgE RF, and $1 / 100$ for IgG RF.

The plates were then incubated with antihuman immunoglobulin labelled with peroxidase (Institut Pasteur Production, Paris). The dilution used was 1/400 for the goat antihuman IgM and sheep antihuman $\operatorname{IgA}, 1 / 800$ for sheep antihuman $\operatorname{IgE}$, and $1 / 1000$ for goat antihuman IgG. After addition of the substrate the plates were read with a spectrophotometer at $492 \mathrm{~nm}$. The results were expressed as:

(mean $\mathrm{OD}$ with $\mathrm{Ag}-$ mean $\mathrm{OD}$ without $\mathrm{Ag}$ ) test serum (mean $\mathrm{OD}$ with $\mathrm{Ag}-$ mean $\mathrm{OD}$ without $\mathrm{Ag}$ ) control serum

where $\mathrm{OD}=$ optical density, $\mathrm{Ag}=$ antigen .

Sera for which this fraction was $>1$ were considered as positive.

Before the IgG RF assay serum samples were treated with dithiothreitol (Sigma).

\section{Results}

RF ISOTYPES DETECTED BY ELISA IN RA IgM RF was present in 92/100 RA sera (73/73 RA sera seropositive by the latex or WR tests and 19 of the 27 seronegative RA) (Fig. 1, Table 1). The correlation coefficient was $r=0 \cdot 69, p<0 \cdot 001$ for the WR or the latex test.

IgA RF was present in 65/100 RA sera (Fig. 1).

IgG RF was found in 66/100 RA sera. The IgG RF levels were lower than the IgA RF and IgM RF levels. Furthermore, the IgG RF upper limit of normal was high because IgG RF was present in a high number of normal sera (Fig. 2).

Sixty eight of 100 RA sera contained low levels of IgE RF (Fig. 2).
Of 92 sera from patients with RA with IgM RF, 65 also had IgA RF. There was a significant correlation between the level of IgM RF and IgA RF ( $r=0 \cdot 66$, $\mathrm{p}<0.001)$, and between IgE RF and IgM RF $(r=0.26, p<0.005)$, but none between IgM RF and IgG RF.

RF ISOTYPES DETECTED BY ELISA IN
CONTROLSERA FROM SUBJECTS WITH OTHER
DISEASES
IgM RF was present in the sera of $13 / 22$ patients with SLE (59\%), but the level was low by comparison with RA sera, as was the case for IgA RF which was present in $8 / 22$ sera $(36 \%)$, IgE RF in $2 / 22$ sera $(9 \%)$, and IgG RF in $6 / 22$ sera $(27 \%$ ) (Table 2 , Figs 1 and 2).

Twenty out of $80(25 \%)$ patients with bronchial asthma had IgM RF, $2 / 80$ (2.5\%) IgA RF, 56/80 (70\%) IgE RF, and $47 / 80$ (59\%) IgG RF. The mean levels of all these isotypes were lower than in RA (Figs 1 and 2).

\section{RF ISOTYPES AND CLINICAL ACTIVITY IN PATIENTS WITH RA}

No significant correlation was found between RF isotypes and age, sex, duration, or onset of the disease.

Using variance analysis IgM RF and IgA RF were shown to have significant correlations with the four grades of activity: $p<0.0015$ and $p<0.02$ respectively (Table 2). Eight patients with RA without IgM RF and $\operatorname{IgA}$ RF had either inactive (four cases) or very recent disease (six to 18 months) (four cases). The presence of circulating immune complexes also correlated with IgM RF and IgA RF: $r=0.69, p<0.001$. Antinuclear antibodies with the highest values $(>1 / 4096)$ were significantly associated with high levels of IgM RF and IgA RF $\left(\chi^{2}=7 \cdot 16, p<0.01\right.$ and $\chi^{2}=5.35, p<0.02$ respectively). Radiographic stages did not correlate with the levels of RF isotypes. Of 25 patients with extraarticular features, 24 presented the four isotypes in their sera. IgM RF, IgA RF, and IgE RF levels were particularly high when compared with RA without extra-articular features $\left(\chi^{2}=1 \cdot 1, p=N S\right.$ for IgM RF, $\chi^{2}=7.4, p<0.01$ for IgA RF, $\chi^{2}=10.0, p<0.001$ for IgE RF). There was no correlation between IgE RF levels and total IgE concentration in the sera. High levels of IgE RF were not associated with allergic symptoms.

The lymphocytes of 47 RA sera were tested for HLA-DR antigens. DR3 antigen, found in 11 patients, was present at a frequency significantly greater than that of the normal population when IgA RF or IgE RF were absent or present at a low level, whereas DR1 and DR2 antigens were associ- 
68 Gioud-Paquet, Auvinet, Raffin, Girard, Bouvier, Lejeune, Monier

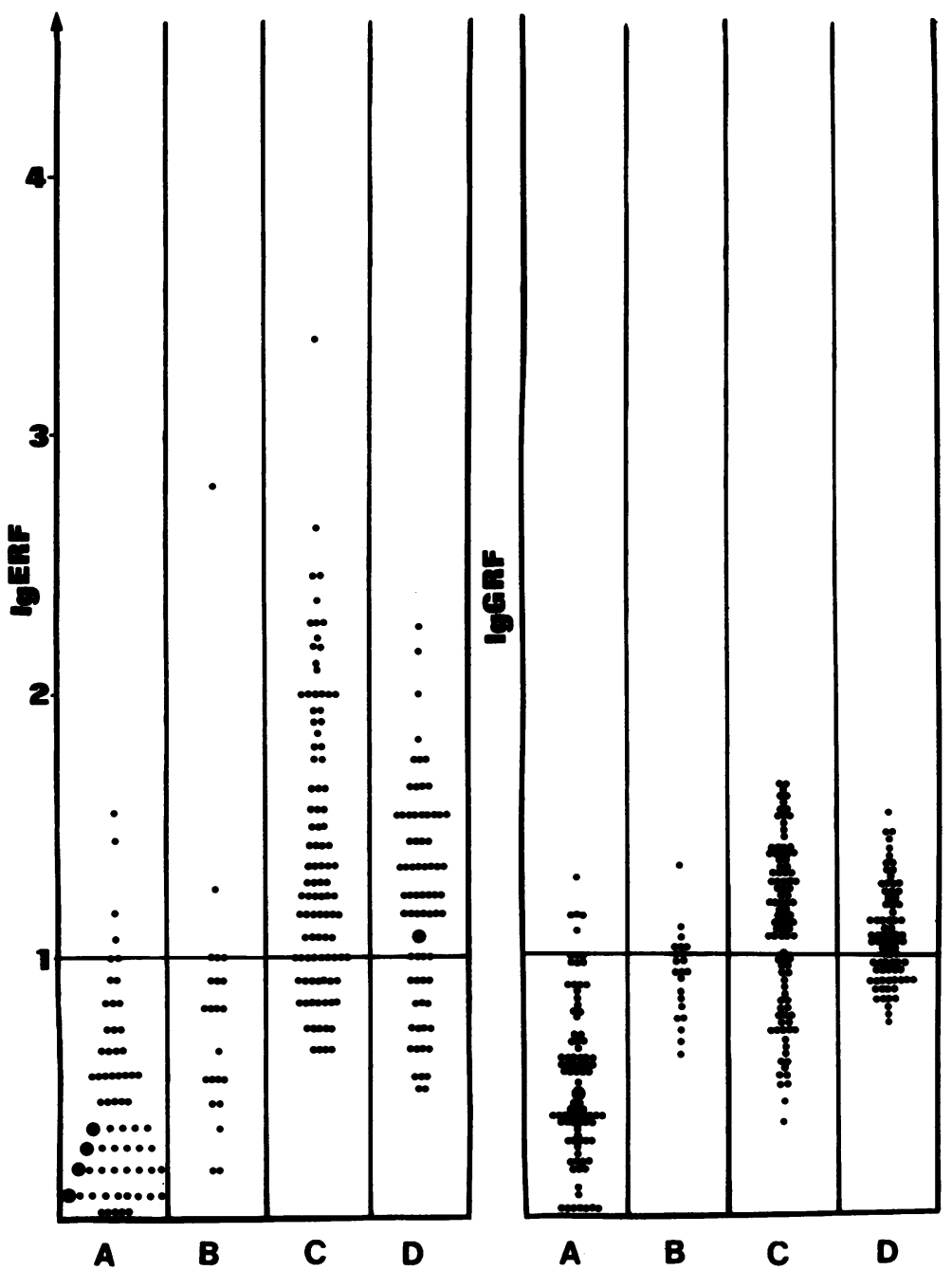

Fig. 2 IgE $R F$ and IgG $R F$ distribution in $(A) 100$ control sera, (B) 22 SLE sera, (C) $100 R A$ sera, and $(D) 80$ bronchial asthma sera by ELISA (OD patient sera/OD upper limit control sera). $\bullet=$ one serum; $\Theta=10$ sera .

Table $2 R F$ levels in 100 patients with $R A$ and relations between $R F$ levels and clinical disease activity. RF levels in 22 patients with SLE and 80 with bronchial asthma

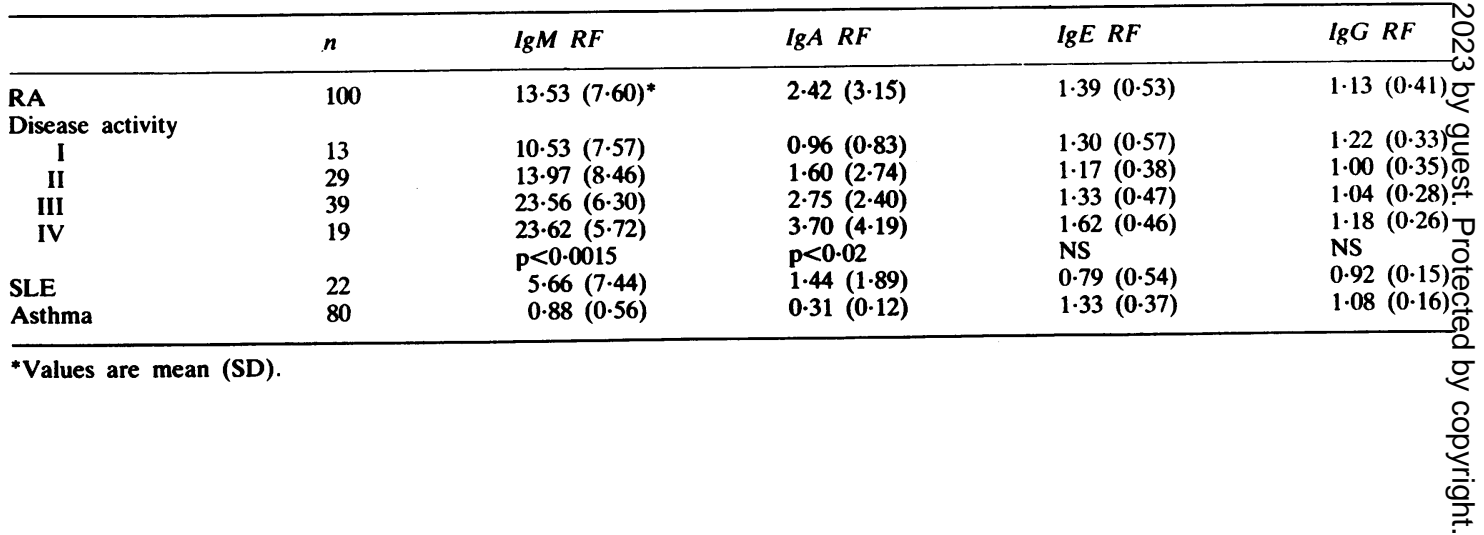


Table $3 H L A-D R$ antigens in 47 RA sera. IgM, IgA, IgE, and IgG RF levels by ELISA

\begin{tabular}{|c|c|c|c|c|c|}
\hline$H L A-D R$ & $n$ & $\operatorname{Ig} M R F$ & $\lg A R F$ & $\lg E R F$ & $\lg G R F$ \\
\hline DR1 & 15 & $24.73(5.78)^{*}$ & $2.76(2.54)$ & $1.61(0.45)$ & $1 \cdot 10(0 \cdot 20)$ \\
\hline 2 & 11 & $19.29(7.93)$ & $2 \cdot 78(2 \cdot 03)$ & $1.34(0.47)$ & $1.11(0.24)$ \\
\hline 3 & 11 & $15.45(8.37)$ & $1.12(1.75)$ & $1 .(49 \quad(0.36)$ & $1.03 \quad(0.35)$ \\
\hline \multirow[t]{2}{*}{4} & 23 & $13.40(8.40)$ & $1 \cdot 12(1.02)$ & $1.32(0.53)$ & $1.07(0.36)$ \\
\hline & & $\begin{array}{l}\mathrm{p}<0 \cdot(06 \\
(\mathrm{NS})\end{array}$ & $\mathrm{p}<0.01$ & $\mathrm{p}<0 .(1) 4$ & NS \\
\hline
\end{tabular}

${ }^{*}$ Values are mean (SD).

ated with the highest levels of $\operatorname{IgM}, \operatorname{IgA}, \operatorname{IgE}$, and IgG RF (Table 3).

\section{Discussion}

ELISA was first used by Vejtorp et al $^{15}$ and Maiolini et $\mathrm{al}^{16}$ for the detection of IgM RF and enables the determination of IgM RF with a greater sensitivity and specificity than agglutination reactions. ${ }^{17} 18$ All seropositive RA sera (with latex or WR tests, or both) used in our study were positive in ELISA, and furthermore, 19/27 (70\%) 'seronegative' RA sera were positive in ELISA. This assay recognised a positivity of $92 \%$ for our RA population, whereas this was only $73 \%$ in latex or WR tests.

In addition, ELISA and radioimmunoassay are able to measure the different isotypes of RF. ${ }^{9}{ }^{19-25}$ The results have been contradictory in the case of IgG RF because of technical problems: IgG RF is present in normal subjects ${ }^{20} 21$ and the control antigen gives a high value as the antigen is an aggregated IgG recognised by the anti-IgG conjugate (McDougal et al eliminated this difficulty by using $\mathrm{Fc}$ as antigen and anti-Fd as conjugate ${ }^{22}$ ). The IgG RF frequency in patients with RA varies between $36 \%$ to $59 \% .{ }^{9}{ }^{19} 23-25$ Our results show low IgG RF values in $66 \%$ of patients with RA $(58 \%$ of seronegative RA and $68 \%$ of seropositive RA).

$\operatorname{IgA} \mathrm{RF}$ was present in $65 \%$ of our RA sera, whereas Bampton et al reported IgA RF in $88 \%$ of their RA sera, ${ }^{19}$ and Tarkowski and Nilsson in only $19 \%$. ${ }^{\prime}$

Mizushima et al, ${ }^{26}$ Zuraw et al, ${ }^{27}$ and Youinou et $a l^{28}$ who studied IgE RF using ELISA, radioimmunoassay, and immunofluorescent techniques respectively, detected them in $16 \%, 79 \%$, and $34 \%$ of the RA sera studied. IgE RF was present in $68 \%$ of our RA sera with levels close to those of Zuraw et al. ${ }^{27}$ IgM RF was present in $59 \%$ of SLE sera, compared with $31 \%$ found with agglutination methods. Figs 1 and 2 illustrate the low values detected in SLE (compared with RA sera) for IgM RF, IgA RF, IgG $\mathrm{RF}$, and $\operatorname{IgE} \mathrm{RF}$ and lower frequency $(59 \%, 36 \%$, $27 \%$ and $9 \%$ ). IgA RF was rare in sera from patients with bronchial asthma, whereas IgE RF was present in $70 \%$ of these patients. Zuraw et al found IgE RF in only $3 / 32$ patients with bronchial asthma. ${ }^{27}$

Our study emphasises the clinical value of measuring individual isotype $\operatorname{IgA} \mathrm{RF}$ and $\mathrm{IgM} \mathrm{RF}$ levels. These have a significant correlation with the clinical activity of the disease and the levels of circulating immune complexes as determined by Clq binding assay.

Nishimaki et al ${ }^{\times}$and Tarkowski and Nilsson" reported a positive correlation with the activity staging and RF whatever the isotype considered (IgM, IgG, or IgA). Pope and McDuffy showed a close association between high levels of RF (IgM or IgG) and circulating immune complexes when detected by $\mathrm{Clq}$ binding assay. ${ }^{29}$

Some authors ${ }^{9}{ }^{30-33}$ have reported an association between IgA RF and RA with systemic symptoms and poor prognosis. We also found $\operatorname{IgA} R F$ in clinically and biologically active RA and also in $80 \%$ of RA with extra-articular features (5/6 with Sjögren's syndrome). Carson et al, ${ }^{1} \mathrm{McD}$ ougal et al, ${ }^{2,3}$ Pope and McDuffy, ${ }^{29}$ Quismorio et al,${ }^{34}$ and Lessard et $a l^{35}$ found an association between IgG RF and disease activity vasculitis, but, like Wernick et al, ${ }^{36}$ we found that IgG RF levels were independent of the clinical pattern.

The clinical significance of IgE RF was studied by Mizushima et al, ${ }^{26}$ who associated these factors with vasculitis $(\mathrm{p}>0 \cdot 01)$. Youinou et al, however, considered that although RA with IgE RF indicated a poor clinical and biological prognosis, IgE RF was not associated with extra-articular features. ${ }^{28}$ In our study IgE RF levels were significantly higher in active progressive RA with extra-articular features.

Interestingly, the determination of HLA-DR antigens enabled us to show a significant association between low IgA RF levels and DR3 and DR4 antigens, whereas DR1 and DR2 antigens were associated with high levels of IgA RF, IgM RF, and IgE RF. The association of HLA-DR4 antigen and IgM RF remains very controversial. ${ }^{37-39}$ We found 
low IgM RF levels in HLA-DR4 RA subjects, but this result did not appear to be significant. Alarcon et al have reported that HLA-DR3 was not present in white RA subjects with high IgA RF (11 RA). ${ }^{40}$ Only one of our 11 DR3 positive RA patients had raised IgA RF levels, but this subject was also DR2 positive, this latter antigen being associated with high IgA RF levels (9/11 RA).

A study of larger populations will be necessary to confirm the role of genetic factors in the regulation of RF isotype level production.

We thank Dr H Betuel (CRTS - Lyon) and Mrs M Cherpin for secretarial assistance.

\section{References}

1 Carson D A, Lawrance S, Catalano M A, Vaughan J H, Abraham G. Radio-immunoassay of IgG and IgM rheumatoid factors reacting with human IgG. J Immunol 1977; 119: 285-300.

2 Meyer O. Les facteurs rhumatoides. Rev Rhum Mal Osteoartic 1984; 51: 219-27.

3 Gripenberg M, Wafin F. Isomaki M, Linder E. A simple enzyme immuno-assay for the demonstration of rheumatoid factor. J Immunol Methods 1979; 31: 109-18.

4 Halbert S P, Karsh J, Anken M. A quantitative enzyme immunoassay for IgM rheumatoid factor using immunoglobulin G as substrate. Am J Clin Pathol 1980; 74: 776-84.

5 Koopman W J, Schrohenloher R E. Salomon A. A quantitative assay for IgA rheumatoid factor. J Immunol Methods 1982; 50: 89-98.

6 Willems F T C, Klasen De Kort C C M. ELISA for rheumatoid factor. Lancet 1978; i: 994-5.

7 Ropes M W, Bennett G A. Lobb S. Jaco R. Jessar R A. Diagnostic criteria for rheumatoid arthritis. 1958 revision. Ann Rheum Dis 1959; 18: 49-53.

8 Nishimaki T, Watanabe S. Yoshida H. Kasukawa R. Immunoglobulin class of rheumatoid factors detected by enzyme linked immunosorbent assay. Clin Rheumatol 1983; 2: 145-51.

9 Tarkowski A. Nilsson L A. Isotype specific measurement of rheumatoid factor with reference to clinical features of rheumatoid arthritis. J Clin Lab Immunol 1983: 12: 129-35.

10 Steinbrocker $\mathrm{O}$, Tracger $\mathrm{C}$ M. Batterman R C. Therapeutic criteria in rheumatoid arthritis. JAMA 1949; 140: 650-62.

11 Zubler R H, Lambert $\mathrm{P} \mathrm{H}$. ${ }^{125} \mathrm{I}-\mathrm{Clq}$ binding test for soluble immune complexes. Ann Rheum Dis 1977; 36 (suppl): 27-32.

12 Tan E M, Cohen A S, Fries J M, et al. The 1982 revised criteria for the classification of systemic lupus erythematosus. Arthritis Rheum 1982; 25: 1271-7.

13 Singer J M, Plotz M D. The latex fixation test. Application to serologic diagnosis of rheumatoid arthritis. Am J Med 1956; 21 : 888-92.

14 Eyquem A, Jacqueline F, Podliachouk L, Franclin J C. Problèmes immunologiques de la polyarthrite rhumatoide ćvolutive. Rev Franc Etudes Clin Biol 1960; 5: 58-64.

15 Vejtorp M, Horer-Madsen M, Halbery P. Enzyme linked immunosorbent assay for determination of IgM rheumatoid factor. Scand J Rheumatol 1979; 8: 65-70.

16 Maiolini R, Ferrua B, Quaranta A, et al. A sandwich method of enzyme immunoassay. J Immunol Methods 1978; 20: 25-34.

17 Faith A, Pontiselli O, Unger A, Panay G S, Johns P. ELISA assays for IgM and IgG rheumatoid factors. J Immunol Methods 1982; 55: 169-77.
18 Quaranta J F. Euller L. Ziegler G. Ferrua B. Maiolini R Masseyeff R. Determination enzymo-immunologique de 1 S. classe des facteurs anti-immunoglobuliniques. Rev Rhum MatOsteoartic 1980; 47: 553-9.

19 Bampton J L M, Cawston T E, Kyle M V, Hazleman B Lס Measurement of rheumatoid factors by an enzyme-linkef immunosorbent assay (ELISA) and comparison with othe methods. Ann Rheum Dis 1985; 44: 13-19.

20 Karsh J, Halbert S P. Klima E. Steinberg A D. Quantitativ determination of rheumatoid factor by an enzyme labeled immunoassay. J Immunol Methods 1980; 32: 115-26.

21 Paluoso T. Milgrom F. IgG rheumatoid factor. Detection b $\vec{C}$ immunoassay in rheumatoid arthritis and normal subjects. $L$ Immunol Methods 1981; 47: 171-81.

22 McDougal J S. Kennedy M S. Hublard M. et al. Immunoassa for $\mathrm{IgG}$ rheumatoid factor with a murine monoclonal anti-FQ antibody. J Lab Clin Med. 1985; 106: 80-7.

23 McDougal J S, Hublard M, McDuffie F C, et al. Comparison of five assays for immune complexes in the rheumatic diseases. Arthritis Rheum 1982; 25: 1156-66.

24 Pope R M, Yoshinoya S, McDuffy S J. Detection of immunê complexes and their relationships to rheumatoid factor in $\Phi$ variety of autoimmune disorders. Clin Exp Immunol 1981; 46: 259-67.

25 Kallerup H E, Egeskjold E M, Graudal H. IgG, IgM and Ig AN rheumatoid factors in healthy adults and rheumatoid patients $b$ an indirect immunofluorescence method. Scand $J$ Rheumato 1979; 8: 1-9.

26 Mizushima Y, Shoji Y, Hoshi K, Kiyohawa S. Detection and clinical significance of $\mathrm{IgE}$ rheumatoid factor. $J$ Rheumatodo 1984; 11: 22-6.

27 Zuraw B L, O'Hair C H. Vaughan J H, Mathison D A, Kat J G. Immunoglobulin-E-rheumatoid factor in the serum of patients with rheumatoid arthritis, asthma and other diseases J Clin Invest 1981; 68: 1610-3.

28 Youinou P, Le Goff P. Mionec P. L'Hostis D. Les polyarthrite rhumatoides avec facteurs rhumatoides de type IgE. Rev Rhun Mal Osteoartic 1982; 49: 453-6.

29 Pope R M, McDuffy S J. IgG rheumatoid factor. Relationshi $\overrightarrow{\vec{B}}$ to seropositive rheumatoid arthritis and absence in seronegative disorders. Arthritis Rheum 1979; 22: 988-98.

30 Dunne J V. Carson D A. Spielberg H L. Vaughan J H. Ig rheumatoid factor in the serum and saliva of patients with. rheumatoid arthritis and Sjögren's syndrome. Ann Rheum Diه్ 1979: 38: 161-6.

31 Elkon K B, Gharavi A E, Patcl B N, Hughes G R V. Franked A. IgA and $\operatorname{lgM}$ rheumatoid factors in serum, saliva and othe secretions. Relationship to immunoglobulin ratios in systemié sicca syndrome and rheumatoid arthritis. Clin Exp Immuno 1983; 52: 75-84.

32 Withrington R H. Teitsson I, Valdimarsson H, Seifert M H응 Prospective study of early rheumatoid arthritis. II. Association of rheumatoid factor isotypes with fluctuations in diseas activity. Ann Rheum Dis 1984; 43: 679-85.

33 Teitsson I Withrington $\mathrm{R} H$, Seifert $M \mathrm{H}$, $\mathrm{V}$ Prospective study of carly rhcumatoid arthritis. I. Prognostie value of IgA rheumatoid factor. Ann Rheum Dis 1984; 43N 673-8.

34 Quismorio F P, Beardmore T, Kaufman R L. Mongan E S. Ig $\oint^{\circ}$ rheumatoid factors and antinuclear antibodies in rheumatoi vasculitis. Clin Exp Immunol 1983; 52: 333-40.

35 Lessard J, Nunner E, Cecere F, McDuffy S, Pope R M Relationship between the articular manifestations of rheumass toid arthritis and circulating immune complexes detected by three methods and specific classes of rheumatoid factors. $\mathcal{L}$ Rheumatol 1983; 10: 411-7.

36 Wernick R, Merryman P, Jaffe I, Ziff M. IgG and IgN rheumatoid factors in rheumatoid arthritis. Arthritis Rheun $\vec{D}$ 1983: 26: $593-8$. 
37 Gran J T, Musby G, Thorsby E. The association between rheumatoid arthritis and the HLA antigen DR4. Ann Rheum Dis 1983; 42: 292-6.

38 Panayi G S, Wooley P M. Batchelor J R. Genetic basis of rheumatoid disease: HLA antigens; disease manifestations and toxic reactions to drugs. $\mathrm{Br}$ Med $J$ 1978; ii: $1326-8$.
39 Scherak O, Smolen J S, Mayr W R. Rheumatoid arthritis and lymphocyte alloantigens HLA-DRw4. J Rheumatol 1980; 7: 9-12.

40 Alarcon S G, Koopman W J, Acton R T, Bayer B O. Clinical and immunogenetic significance of IgA rheumatoid factor. Arthritis Rheum 1983; 26: S51. 